\title{
Paired-laser photogrammetry as a simple and accurate system for measuring the body size of free-ranging manta rays Manta alfredi
}

\author{
Mark H. Deakos ${ }^{1,2, *}$ \\ ${ }^{1}$ The Hawaii Association for Marine Education and Research, PMB\#175, 5095 Napilihau St. 109B, Lahaina, Hawaii 96761, USA \\ ${ }^{2}$ University of Hawaii at Manoa, 2500 Campus Road, Honolulu, Hawaii 96822, USA
}

\begin{abstract}
Morphometrics are useful for describing and managing animal populations, but measurements can be difficult to obtain, especially on large free-ranging aquatic animals. The accuracy and precision of paired-laser photogrammetry were tested as a simple and non-invasive remote sensing system for measuring the body size of free-ranging, resident manta rays Manta alfredi, a newly described species that is poorly understood. Based on repeated measurements of a pipe of known size, the paired-laser system proved accurate (mean error of $0.39 \%$ ) and precise $(\mathrm{CV}=0.54 \%)$. Repeated measurements on 154 different manta rays visiting a cleaning station off Maui, Hawaii, produced a mean CV of $1.46 \%$. Disc length (DL) measurements were more precise than disc width (DW) measurements, and an empirically derived disc ratio (DR) function was applied to convert DL to DW measurements for standard comparison with other studies. Sexual dimorphism was present with the largest female (3.64 m DW) 18\% larger than the largest male (3.03 m DW). Sexual maturity in females, based on evidence of pregnancy and mating scars, was conservatively determined to be $3.37 \mathrm{~m} \mathrm{DW}$. The DW at which $50 \%$ of the males were likely to be mature (based on clasper length) was between 2.7 and $2.8 \mathrm{~m}$. The absence of individuals $<2.5 \mathrm{~m} \mathrm{DW}$ suggests that age class segregation occurs in this population. Paired-laser photogrammetry proved to be a simple, non-invasive, accurate, and precise method for sizing free-ranging manta rays. Repeated measurements on known individuals over time could provide population growth parameters needed for adequate management of this poorly understood species.
\end{abstract}

KEY WORDS: Morphometrics · Photogrammetry · Manta ray · Manta alfredi • Body size • Sexual maturity · Hawaii

- Resale or republication not permitted without written consent of the publisher

\section{INTRODUCTION}

Body size measurements or morphometrics are important components for understanding the life history of an organism. Morphometrics have been used to study individual growth (e.g. Clark et al. 2000), physical and sexual maturity (e.g. Waters \& Whitehead 1990), phenotypic differences in closely related species (e.g. Perryman \& Lynn 1993), and size class segregation in a population (e.g. Cubbage \& Calambokidis 1987). Identifying the existence of sexual dimorphism in a population through morphometrics can help to understand reproductive strategies, intrasexual competition, and mate choice (e.g. Breuer et al. 2007).
Obtaining morphometrics on free-ranging animals can be challenging, especially if the animals are large in size, and particularly if they live in aquatic environments. Most methods are intrusive, disruptive, and usually involve the capturing or killing of the animal. The ability to obtain size measurements remotely eliminates many of these risks.

Photogrammetry is a non-invasive, remote sensing technique that uses photography or digital imagery to measure objects or, in the case of animals, morphometrics. The technique has been used to measure the body length of large marine animals such as whales (Cubbage \& Calambokidis 1987, Best \& Ruther 1992, Spitz et al. 2000), dolphins (Perryman \& Lynn 1993), 
seals (Bell et al. 1997), and sharks (Klimley \& Brown 1983). With photogrammetry, measurements can be collected quickly, with minimal disturbance to the animals or their associates. However, photogrammetric techniques can be expensive and cumbersome, requiring an aircraft (e.g. Cosens \& Blouw 2003), a boat with a tall mast (e.g. Dawson et al. 1995), or multiple cameras operating simultaneously (e.g. Klimley \& Brown 1983). Paired-laser photogrammetry uses 2 parallel laser pointers mounted onto a single camera to project 2 points of light onto a target, showing a scale of known size from which the size of the target can be inferred. The technique is relatively simple, compact, and can be implemented by a single photographer. It has been used to measure morphometrics on large free-ranging animals such as horn length in Alpine ibex Capra ibex (Bergeron 2007) and the dorsal fins of killer whales Orcinus orca (Durban \& Parsons 2006) and bottlenose dolphins Tursiops truncates (Rowe \& Dawson 2008). It has also been used underwater, with moderate success, to measure small fish at close range (Yoshihara 1997, Mueller et al. 2006). The present study investigated the usefulness of underwater paired-laser photogrammetry for measuring one of the largest fish in the oceans, the manta ray.

Manta rays are the largest ray in the Mobulidae family and are still poorly understood. They feed on small planktonic organisms such as euphausiids and copepods (Notarbartolo-di-Sciara 1987, Last \& Stevens 1994, Homma et al. 1999, Clark 2001) and possibly on small shrimp, crabs, and fish (Bigelow \& Schroeder 1953). They are ovoviviparous and are believed to give birth to a single live young every 2 to $3 \mathrm{yr}$ (Homma et al. 1999) following a gestation period of 12 to $14 \mathrm{mo}$ (Marshall et al. 2006). Following parturition, the pup is weaned immediately with no further parental care (Uchida et al. 2008). Natural predators include large sharks (Homma et al. 1999) and killer whales Orcinus orca (Visser \& Bonoccorso 2003), depending on the region.

The genus Manta was thought to consist of just a single species, Manta birostris, but recent evidence from morphology has confirmed a second species in the genus, Manta alfredi (Marshall et al. 2009). M. birostris, sometimes referred to as 'oceanic mantas,' can grow to a disc width (DW; distance between the wing tips, Francis 2006) of $6.7 \mathrm{~m}$ (Bigelow \& Schroeder 1953), and possibly as large as $9.1 \mathrm{~m}$ (Compagno 1999). These mantas occur in temperate, sub-tropical, and tropical waters globally, spending the majority of their time in deep water, paying occasional visits to coastal areas with productive upwellings, oceanic islands, and offshore pinnacles and seamounts (Bigelow \& Schroeder 1953, Compagno 1999, Marshall et al. 2009).
Manta alfredi, referred to in the present study as resident mantas, have been observed in the Pacific, Atlantic, and Indian Oceans between latitudes $30^{\circ} \mathrm{N}$ and $30^{\circ} \mathrm{S}$ (Marshall et al. 2009). Smaller and more tropical than their oceanic relatives, they are more likely to be observed in shallow coastal areas (Notarbartolo-diSciara \& Hillyer 1989) with rocky and coral reef habitats near productive upwellings, as well as around tropical islands, atolls, and bays (Marshall et al. 2009). In some parts of the world they can be reliably seen congregating around rich food sources and cleaning stations (Homma et al. 1999, Clark 2001, Dewar et al. 2008). Cleaning stations consist of specific locations along the reef where individuals solicit host cleaner fish that feed on parasites and other unwanted materials on their skin (Losey 1972).

Worldwide, only a handful of resident manta rays have been successfully measured for morphology. In waters off southern Mozambique, the smallest freeswimming individuals were estimated at $1.5 \mathrm{~m} \mathrm{DW}$ and the largest at $5.5 \mathrm{~m} \mathrm{DW}$ (Marshall et al. 2009). Males in this region appear to mature around $3 \mathrm{~m} \mathrm{DW}$, while females in coastal waters off South Africa appear to mature at approximately $3.9 \mathrm{~m} \mathrm{DW}$ (Marshall et al. 2009).

The aim of the present study was to examine the practicality, accuracy, and precision of paired-laser photogrammetry as a simple, non-invasive, remote sensing system for measuring free-ranging, resident manta rays from a population off Maui, Hawaii. The maximum size of male and females at physical maturity and their minimum size at sexual maturity were quantified, providing new information about the biology and ecology of this species.

\section{MATERIALS AND METHODS}

Study area and population. All manta ray surveys were conducted opportunistically over a $3 \mathrm{yr}$ period between 2007 and 2009 at a single manta ray cleaning station off the west coast of the island of Maui, Hawaii. Approximately $450 \mathrm{~m}$ offshore, a region $8000 \mathrm{~m}^{2}$ (200 $\times$ $400 \mathrm{~m}$ ) in size with a depth range of 5 to $30 \mathrm{~m}$ was chosen as the monitoring boundary for the study area because of the high reliability of observing manta rays and thereby maximizing encounter rates. The habitat consists primarily of fringing coral reef that extends approximately $550 \mathrm{~m}$ away from the shoreline. The main cleaning stations were situated near the starting point of the survey where the Hawaiian cleaner wrasse Labroides phthirophagus and saddle wrasse Thalassoma duperrey remove small copepod parasites from soliciting manta rays. Manta ray mating trains were also observed in this area consisting of a single female pursued by one or more males (Yano et al. 1999). The 
exact location of the site is being withheld to avoid commercial exploitation of this unique area.

Equipment. Two underwater, green laser pointers (Lasermate Professional; output power $<5$ mw, wavelength $=532 \mathrm{~nm}, 180 \mathrm{~mm}$ in length, $25 \mathrm{~mm}$ in diameter) were mounted in parallel with their centers $600 \mathrm{~mm}$ apart onto a $160 \times 680 \times 5 \mathrm{~mm}$ aluminum plate. A $600 \mathrm{~mm}$ separation provided a reference scale small enough to measure the smallest manta ray in the population but large enough to minimize error while maintaining portability. The platform was mounted to the bottom of a Sea \& Sea VX-HC1 underwater housing (Fig. 1). The housing enclosed a Sony HDR-HC1, high definition video camera with a lens focal zoom length of 5.1 to $51 \mathrm{~mm}$ (equivalent to 48 to $480 \mathrm{~mm}$ on a $35 \mathrm{~mm}$ still camera), lens aperture F/1.8-2.1, and 2.76 megapixel effective still resolution. The camera was fitted with a wide-angle lens attachment (68 mm diameter, $41 \mathrm{~mm}$ length, 0.7× magnification). Allen screws, threaded around each laser-mounting bracket, allowed for fine-scale adjustments of each laser pointer to ensure they were exactly parallel.

Accuracy and precision. Potential sources of measurement error include: (1) image distortion caused by light refraction and the wide-angle lens; (2) non-parallel alignment of the lasers; and (3) parallax error.

Image distortion: Image distortions can occur when light refracts as it passes at an angle from water (refractive index $\sim 1.00$ ) to air (refractive index 1.33) inside the underwater camera housing. Further distortion occurs when the light passes through the wide-angle lens. Wide-angle lenses are designed to severely bend rays of light around the periphery of the field of view (Swaminathan \& Nayar 1999), with pixels toward the center of the image being the least distorted and pixels toward the edges of the image being the most distorted. Some of the distortion, in particular around the edges of the picture, readjusts slightly due to the refraction occurring in air trapped in the camera hous-

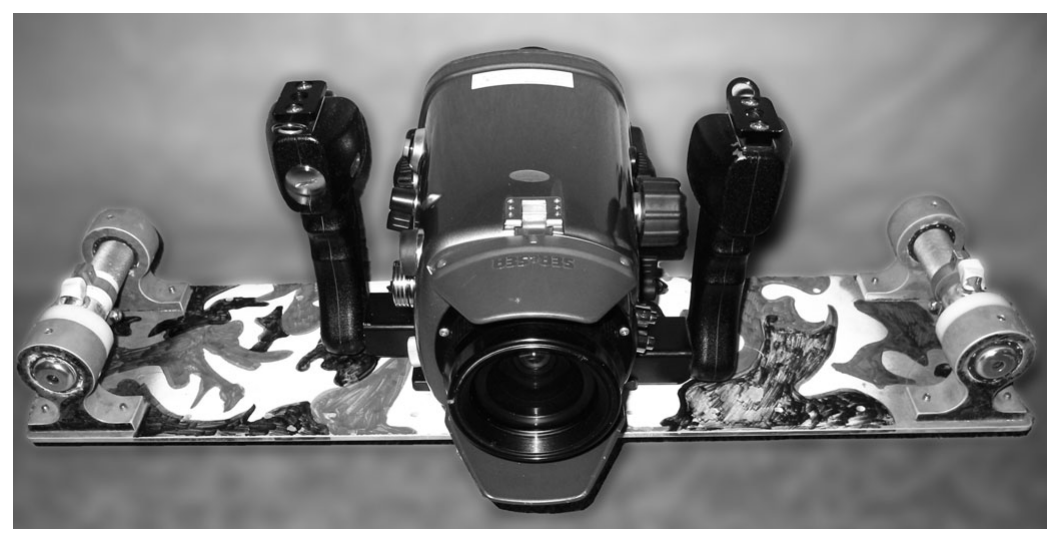

Fig. 1. Pair of green, underwater laser pointers mounted in parallel to an underwater video housing ing (between water and lens) before the light reaches the lens. By approximating the amount of distortion occurring in the image, a correction factor can be applied to compensate for the distortion.

To quantify the amount of distortion that was occurring, a piece of graph paper was photographed underwater and the image examined in Adobe Photoshop ${ }^{\circledR}$. The image was composed of 16 columns and 10 rows of squares for a total of 160 squares. Since the squares at the center of the image had the least distortion, the dimensions of these squares were used to represent the expected dimensions of a non-distorted square (as if the image had been photographed with a flat lens). The diagonal length across 2 of these center squares was measured (in pixels) using the Adobe Photoshop ${ }^{\circledR}$ line tool. Additional lengths were taken diagonally across 4, 6, and 8 squares with the center of the diagonal passing over the center of the image, essentially expanding the diagonal measurement by 2 square increments. The expected, undistorted lengths for these dimensions were calculated by multiplying the undistorted diagonal length of the 2 center squares by 2,3 , and 4 , respectively.

The expected, undistorted lengths were plotted along the $y$-axis. The actual measured lengths were plotted on the $x$-axis. The data were fitted with a regression curve and a Pearson correlation coefficient was calculated to determine its fit. The function of the curve was applied to all measurements to correct for the distortion caused by the light refraction and wide-angle lens.

Parallel alignment of lasers: Non-parallel alignment of the laser pointers can cause the spacing between the points of light to change depending on the distance from the target, creating inaccurate measurements. To ensure the lasers were parallel, a plastic pipe with 2 marks spaced $600 \mathrm{~mm}$ apart was placed on the ocean bottom at a depth of approximately $10 \mathrm{~m}$. With the paired-laser system in hand, a SCUBA diver positioned over the center of the pipe adjusted the Allen screws so that the points of light projected exactly onto the markings (Fig. 2A). The laser pointers were confirmed to be parallel when the spacing between the points of light remained $600 \mathrm{~mm}$ as the diver moved towards and away from the pipe. On 4 occasions (12 Aug 2008, 21 Sep 2008, 9 Oct 2008, and 9 Jan 2009) the laser pointers were removed from the holding brackets, remounted, and the spacing adjusted to ensure they were parallel.

Parallax error: Parallax error can be a problematic source of error with pairedlaser photogrammetry (e.g. Durban \& Parsons 2006). This occurs when the laser projections are not perpendicular 

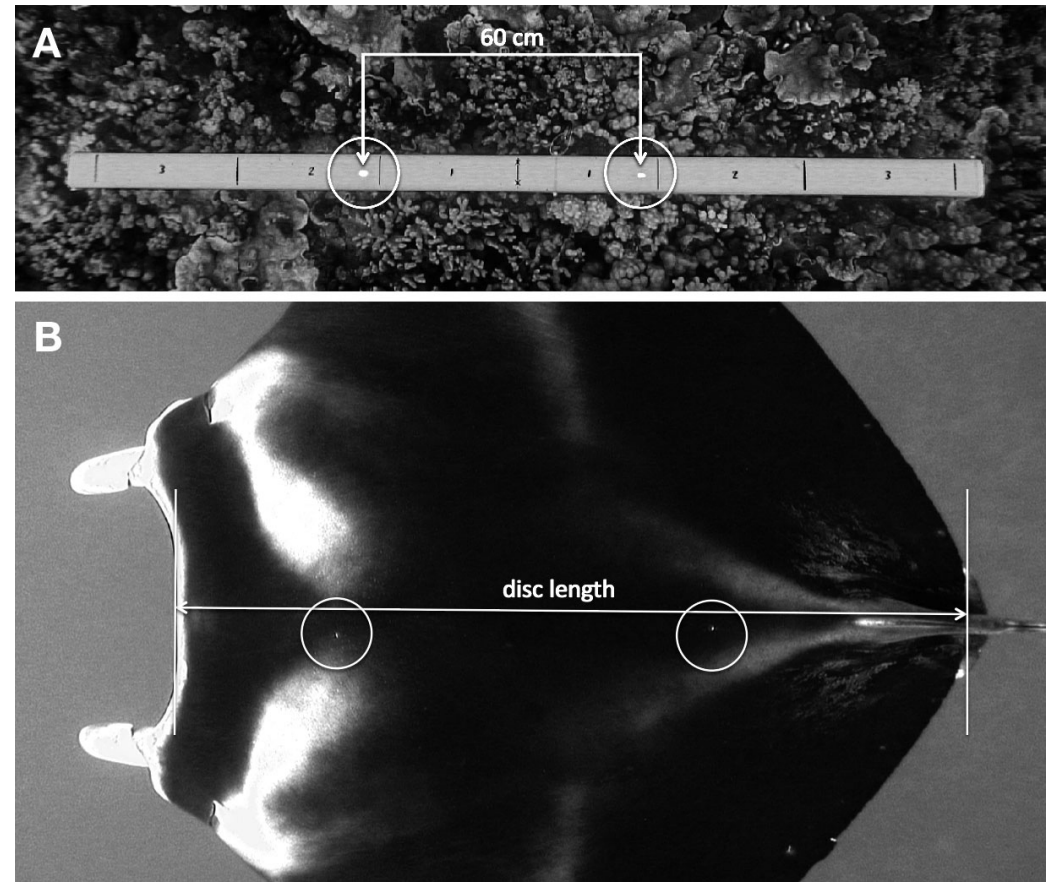

Fig. 2. (A) Pipe of known length being measured on the ocean floor showing the projected points of light $60 \mathrm{~cm}$ apart; (B) a manta ray Manta alfredi from above showing the projected points of light along the spinal axis of the disc from which a disc length measurement can be obtained

to the surface being measured. To investigate how the measurement of an object of known length varies with the horizontal angle of the target to the axis of the lasers (parallax), measurements of a $1940 \mathrm{~mm}$ pipe were taken with the diver positioned above the end of the pipe rather than over the center. The distance of the diver above the end of the pipe was calculated by multiplying the tangent of the desired parallax angle (in this case $80,70,60,50$, and $40^{\circ}$ ) by half the length of the pipe $(970 \mathrm{~mm})$ to produce parallax angles of 10 , $20,30,40$, and $50^{\circ}$ off the perpendicular axis. The pipe was measured 5 times at each angle. The lens correction function was applied to each measurement and a mean percent error was calculated for all measurements at each angle.

Pipe measurements: Accuracy and precision of the paired-laser system were determined by measuring a pipe of $1940 \mathrm{~mm}$ on 4 separate days over a 5 mo period. The diver positioned himself over the center of the pipe at a distance that would allow the full length of the pipe to be captured within the camera's field of view along the horizontal plane. With the pipe perpendicular to the direction of the laser projections, the 2 points of light were projected onto the center of the pipe and a photograph was taken using the minimum focal length of $5.1 \mathrm{~mm}$ (Fig. 2A). After a measurement was taken, the diver moved a short distance away before repositioning to take a second independent measure- ment. After a minimum of 4 independent measurements, the pipe was moved to a new location and a new series of measurements was taken. Accuracy was determined by measuring the percent error of the estimated length against the known length of the pipe. Precision was measured by calculating the percent coefficient of variation (CV) from repeated measurements of the pipe.

Manta ray measurements. Surveys: A survey consisted of a 55 to $75 \mathrm{~min}$ SCUBA dive with a beach entry to the study site. Each survey began from the exact same location. From this starting point, a rectangular search pattern was initiated, enclosing an area approximately $8000 \mathrm{~m}^{2}(200 \times 400 \mathrm{~m})$. The water depth ranged from 6 to $30 \mathrm{~m}$. When manta rays were encountered, disc length (DL) and DW measurements were attempted.

DL is defined here as the length from the tip of the snout to the posterior edge of the pectoral fins (Francis 2006). To measure DL, the diver positioned above the manta ray such that its dorsal plane was perpendicular to the direction of the laser projections, and the DL was captured along the horizontal axis of the field of view. A photograph was taken with the points of light projected onto the center of the anteroposterior axis of the disc (Fig. 2B). The diver then turned the camera $180^{\circ}$ horizontally and repositioned above the manta ray before each repeated measurement. When repositioning, care was taken to stay out of the manta ray's field of view so as not to surprise the animal and cause it to flee. At least 4 independent measurements were attempted on each manta ray when possible.

The same method applied when measuring the DW, except that the wing tips of the manta ray were aligned with the horizontal axis of the field of view. A photograph was taken with the points of light projected onto the center of the mediolateral axis of the disc. It was important that the photograph be taken when both wings were completely open so as not to underestimate the DW.

Sizes were taken from above the manta ray to: (1) minimize disturbance to the manta ray since they do not appear to see directly above their dorsal plane; (2) eliminate any chance of projecting a point of light into the manta ray's eye since the eyes are not visible from above; and (3) minimize parallax error since the diver, from above, is better able to align the laser projections perpendicular to the axis of the manta ray. 
Precision of the paired-laser system was assessed by calculating the CV from repeated measurements taken on the same animal during the same survey and across different surveys.

Disc ratio: The relationship between DW and DL was examined by dividing the DW by its corresponding DL to obtain a disc ratio (DR). The mean DR was compared between females and males to determine if this proportional relationship was the same across sexes, and the same comparison was made between adult and juvenile males to determine if the proportional relationship was constant across age classes. The measured DW for each manta ray was plotted against its corresponding DL and fitted with a linear regression curve. The function of the regression curve was used to convert measurements of DL to an estimate of DW so that direct comparisons could be made with other studies.

Photo-processing: Each photograph of a manta ray size was examined in Adobe Photoshop ${ }^{\circledR}$. If the dorsal plane of the manta ray in the image did not appear perpendicular to the axis of the laser projections, the image was discarded to eliminate parallax error. For all other images, the number of pixels between the 2 points of light and between each end of the target was measured using the line tool. The length of the target (in pixels) was divided by the distance between the points of light (in pixels) and multiplied by the known distance between the points of light $(600 \mathrm{~mm})$ to obtain the length of the target.

Photo-identification: Photo-identification involves taking photographs of distinctive characteristics from an animal in order to identify and track individuals of a wild population over time. This technique has been used extensively with large and long-lived vertebrates (for review see Würsig \& Jefferson 1990) for population estimates (e.g. Graham \& Roberts 2007), life history information (e.g. Brault \& Caswell 1993), lifespan information (e.g. Langtimm et al. 2004), migration patterns (e.g. Calambokidis et al. 1996), and social relationships (e.g. Bejder et al. 1998) of recognized individuals. Since each manta ray possesses a distinct pattern of spots on the ventral surface that are present from birth (Marshall et al. 2008), and the pattern appears to remain unchanged over time (Homma et al. 1999, Yano et al. 1999, Clark 2001), this species is well suited for photo-identification studies.

During each manta ray encounter, attempts were made to photograph the ventral spot pattern of each individual sighted. Manta rays frequently make close passes near a diver allowing the diver to be positioned such that a ventral identification photograph can be taken. When possible, the genital area was also captured in the photograph for sex identification. Immediately after each manta ray was photo-identified, a hand signal was also photographed to indicate the sex and age class of that individual. Photo-identifications were taken prior to moving above the animal for size measurements.

Photographs were downloaded to a MacBook Pro computer and the best photo-identification for each individual from a survey was imported into Finbase, a publicly available photo-identification program created in Microsoft Access (Adams et al. 2006). The photo was matched against photos of all previously identified individuals from the study site and determined to be a match or a new individual. A detailed catalog was kept of each individual in the population and its sighting history. The very distinct markings on the underside of each manta ray make the likelihood of missing a match, or falsely identifying a match, unlikely.

Sex and age class: Since claspers are present and visible in males from birth (Marshall et al. 2008), the sex of the manta ray was determined by the presence or absence of claspers. Females were documented as sexually mature if they were obviously pregnant or showed visible mating scars (spot scarring and abrasions usually visible on the dorsal side of the end of the left wing but occasionally seen over the tip of the right wing or ventral side of the wing tips; Marshall 2009). Pregnant females close to term are exceptionally rotund in girth and could be identified quite easily. A female that appeared to be pregnant but was questionable was not given an age class. A female being pursued by multiple males in a mating train was documented as a nuclear female.

Among males, calcification of the claspers occurs rapidly over a relatively narrow range of growth (White et al. 2006), with the majority of calcification occurring once the claspers have extended beyond the length of the pelvic fins (A. Marshall pers. comm.). Since the onset of clasper calcification in many shark species coincides with a rapid rate of clasper growth and gonadal maturation (e.g. Jones et al. 2008), claspers extending beyond the pelvic fins were used as a reliable indicator of sexual maturity.

Statistics. Pearson correlation coefficients were calculated for both linear regressions describing the relationship between undistorted and actual measured lengths, and the relationship between the DW and DL of individual manta rays. The precision of a single measurement was tested using a Wilcoxon signedrank test for matched pairs by comparing the first measurement of a manta ray with the mean of repeated measurements on the same manta ray. The variability of repeated DL and DW measurements were compared using a Mann-Whitney $U$-test. This test was also used to compare the mean DR between females and males, and between adult and juvenile males. Significance for all statistical tests was set at $\mathrm{p}<0.05$. Confidence intervals are reported at $95 \%$. 


\section{RESULTS}

\section{Accuracy and precision}

The diagonal distance across the 2 center squares in the underwater photograph of the graph paper was 245 pixels. Therefore, expected diagonal distance across 4,6 , and 8 of the center squares was estimated as $2 \times 245=490,3 \times 245=735$, and $4 \times 245=980$ pixels, respectively. Actual measured diagonal values were 491, 741, and 992 pixels, respectively. The expected, undistorted lengths were plotted against the actual, measured lengths (Fig. 3). The linear regression of best fit produced a Pearson correlation coefficient of $1.0(\mathrm{df}=3, \mathrm{p}<0.001)$.

Five pipe measurements were made from angles of $10,20,30,40$, and $50^{\circ}$ away from the perpendicular axis to the center of the pipe. This resulted in mean parallax errors of $-4.92,-6.13,-8.79,-22.25$, and $-39.29 \%$, respectively. A pipe $1940 \mathrm{~mm}$ in length was measured on 5 separate occasions over a 6 mo period for a total of 92 independent measurements. Without a wide-angle lens correction function applied, the overall mean estimated pipe length was $1967 \mathrm{~mm} \mathrm{(95 \%}$ $\mathrm{CI}= \pm 2, \mathrm{CV}=0.61 \%$ ). With the lens correction applied, the estimated mean length was $1938 \mathrm{~mm}(95 \% \mathrm{CI}=$ $\pm 2, \mathrm{CV}=0.54 \%$ ). The lens correction function reduced the mean error from 1.39 to $0.39 \%$ and reduced the maximum error from 2.76 to $1.43 \%$.

\section{Manta ray measurements}

\section{Surveys}

A total of 87 surveys were conducted during which the DLs of 274 manta rays were measured. The DW of 82 of these manta rays was also measured. Photoidentification matching revealed 154 of these manta rays were distinct individuals. The variance of repeated DW measurements on the same individual (mean CV $=3.05 \%$ ) was significantly greater than the variance of repeated DL measurements on the same individual (mean $\mathrm{CV}=1.46 \%$; Mann-Whitney $U$-test, $\left.Z_{(0.05)}=-2.692, \mathrm{n}=264,51, \mathrm{p}=0.007\right)$, indicating that $\mathrm{DL}$ is a more precise measurement than DW.

\section{Disc ratio}

The mean DR for all 82 individuals measured was $2.33(95 \% \mathrm{CI}= \pm 0.02)$. No significant differences were found between the DR of females and males, or between adult and juvenile males (Table 1). For each individual, the measured DW was plotted against its

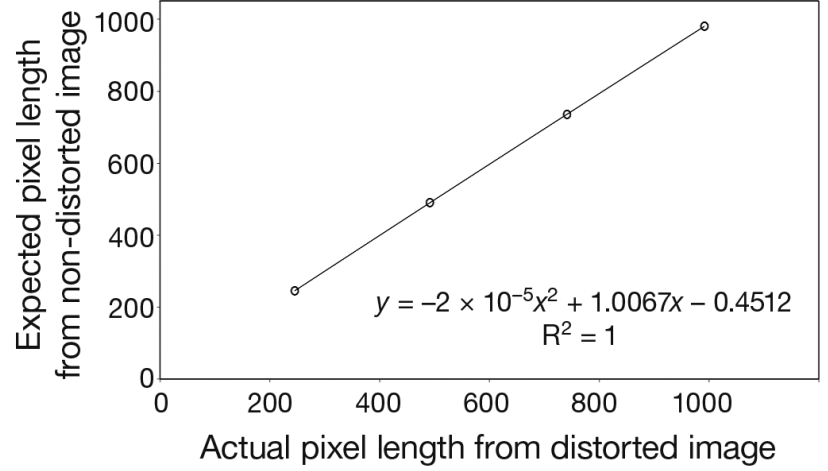

Fig. 3. Plot of the expected, undistorted length of an object (in pixels) if measured with a flat lens against the actual measured length of the same object (in pixels) distorted by the wide-angle lens. The data are fitted with a linear regression equation

corresponding DL (Fig. 4). The linear regression of best fit produced a Pearson correlation coefficient of $0.923(\mathrm{df}=63, \mathrm{p}<0.001)$. The relationship between DW and DL was best described by the following linear regression:

$$
\mathrm{DW}=1.958 \mathrm{DL}+0.469\left(\mathrm{r}^{2}=0.923\right)
$$

Results of a Wilcoxon signed-rank test found no differences between the first measured DL of an individual manta ray and the mean of repeated independent DL measurements of the same individual $(Z=-0.632, \mathrm{n}=$ $274, \mathrm{p}=0.527$ ).

\section{Sex and age class}

Of the 154 individual manta rays measured in this population, 71 (46\%) were females and 83 (54\%) were males (Fig. 5). Females were on average significantly larger than males (Mann-Whitney $U$-test, $Z=-0.0867$, $\mathrm{n}=71,83, \mathrm{p}<0.001)$. The largest female (3.64 m DW)

Table 1. Manta alfredi. Comparison of the mean disc ratio (DR) between male and female and between adult male and juvenile male manta rays

\begin{tabular}{|lccc|}
\hline & Mean DR & $\mathrm{n}$ & $\% \mathrm{CV}$ \\
& & & \\
\hline Males & $2.34^{\mathrm{a}}$ & 37 & 3.13 \\
Females & $2.33^{\mathrm{a}}$ & 27 & 3.50 \\
Adult males & $2.33^{\mathrm{b}}$ & 23 & 3.24 \\
Juvenile males & $2.35^{\mathrm{b}}$ & 12 & 3.46 \\
All individuals & 2.33 & 64 & 3.27 \\
Mann-Whitney $\boldsymbol{U}$-test & & & \\
${ }^{\mathrm{a}} Z=-0.768, \mathrm{df}=63, \mathrm{p}=0.442$ & & \\
${ }^{\mathrm{b}} Z=-0.452, \mathrm{df}=34, \mathrm{p}=0.668$ & & \\
\hline
\end{tabular}




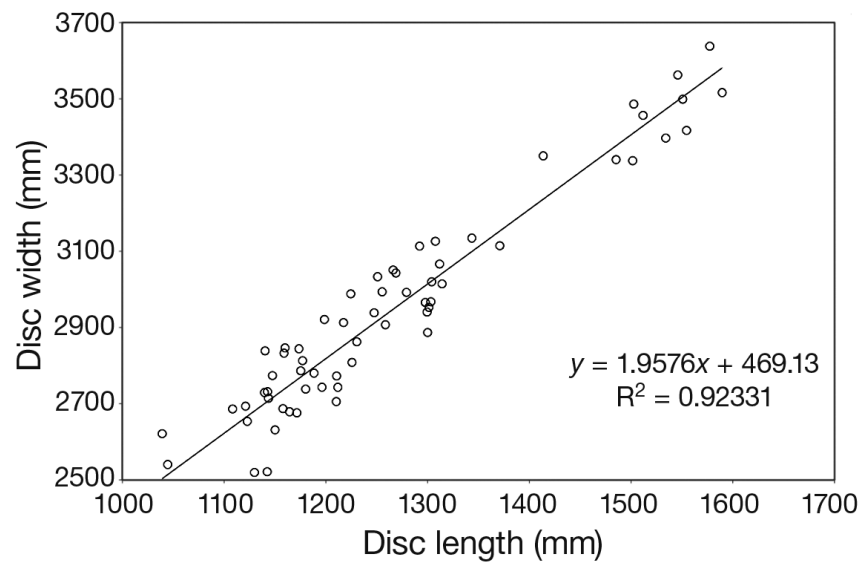

Fig. 4. Manta alfredi. Manta ray disc width $(\mathrm{n}=64)$ plotted against length

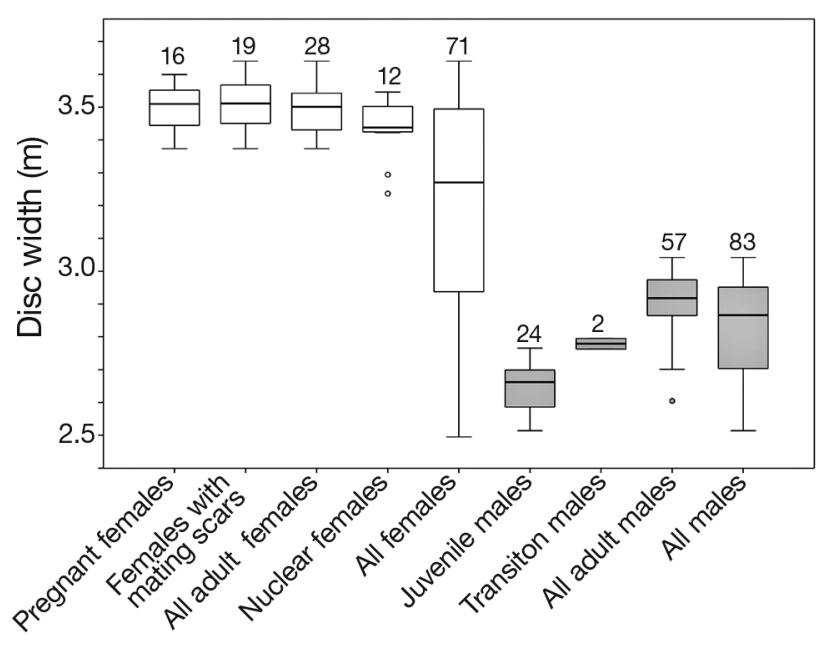

Fig. 5. Manta alfredi. Distribution of manta ray disc widths. Heavy black lines $=$ means, box boundaries $=25$ th and 75 th percentiles, whiskers = smallest and largest observed values that are not statistical outliers, circles $=$ outliers, numbers $=$ sample sizes

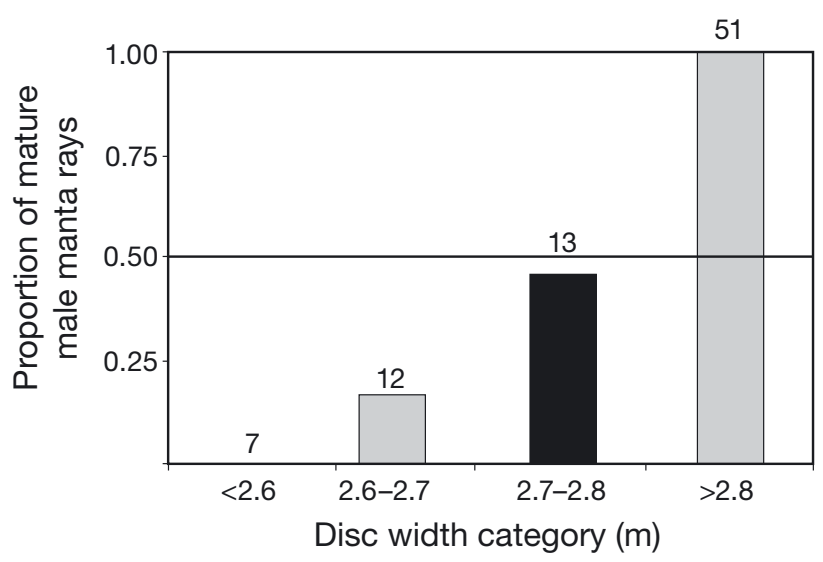

Fig. 6. Manta alfredi. Proportion of males that is sexually mature in each size category. The black column indicates the size category for which $\sim 50 \%$ of the males can be considered mature $\left(\mathrm{DW}_{50}\right)$. Numbers above each column indicate sample size was $18 \%$ larger than the largest male (3.00 m DW). The smallest female (2.50 m DW) was only slightly smaller than the smallest male (2.51 m DW).

The smallest pregnant female at $3.37 \mathrm{~m} \mathrm{DW}(\mathrm{n}=16)$ was also the smallest female with visible mating scars ( $\mathrm{n}=19$ ). Using the size of this female as a conservative minimum size for sexual maturity in females, at least $48 \%$ of the females measured in this population were likely to be mature. The smallest female observed in a mating train was $3.24 \mathrm{~m} \mathrm{DW}(\mathrm{n}=12)$. One third of all nuclear females were never observed pregnant or to have mating scars.

The smallest adult male was estimated at $2.60 \mathrm{~m} \mathrm{DW}$ $(\mathrm{n}=57)$ and the largest juvenile male was estimated at $2.77 \mathrm{~m}$ DW $(\mathrm{n}=24)$. Transition males, whose claspers were exactly even with the edge of the pelvic fins, were rare. Only 2 were measured, with a DW of $2.76 \mathrm{~m}$ and $2.80 \mathrm{~m}$. When DW among males was separated into $0.1 \mathrm{~m}$ incremental categories, the DW category at which approximately $50 \%$ of the males were considered mature $\left(\mathrm{DW}_{50}\right)$ was 2.7 to $2.8 \mathrm{~m}$ (Fig. 6).

\section{DISCUSSION}

\section{Accuracy and precision}

When measuring a target of known size, the pairedlaser photogrammetry system was accurate to a mean error of $0.39 \%$ ( 0 to $1.43 \%$ ) and precise to a mean CV of $0.54 \%(0.02$ to $4.01 \%)$. This is similar or better than reports for other photogrammetric systems, with accuracy ranging from 0.47 to $6.6 \%$ (Cubbage \& Calambokidis 1987, Perryman \& Lynn 1993, Spitz et al. 2000, Cosens \& Blouw 2003, Bergeron 2007) and precision ranging from 0.84 to $9.03 \%$ (Klimley \& Brown 1983, Cubbage \& Calambokidis 1987, Gordon 1990, Best \& Ruther 1992, Perryman \& Lynn 1993, Dawson et al. 1995, Spitz et al. 2000, Cosens \& Blouw 2003).

Potential sources of error with the paired-laser system were easily controlled for by (1) using sturdy mounts to ensure the laser pointers remained parallel, (2) discarding images showing evidence of parallax, and (3) applying a simple, empirically determined correction function to control for image distortion caused by light refraction and the wide-angle lens.

For measuring manta ray sizes, the paired-laser photogrammetric system proved to be simple to use. A single diver was able to take multiple measurements with little or no change to the manta ray's behavior. Occasional reactions by a manta ray during measurements usually occurred when the manta ray performed an abrupt change in direction (e.g. when being bitten by a cleaner wrasse), thus bringing the diver into view and causing the manta ray to move rapidly away. 
Although multiple measurements should be taken for insurance, in some situations, such as when multiple animals in a mating train pass through the area rapidly, time may only allow for a single measurement to be taken per individual. The first measurement proved to be just as precise as the mean of repeated measurements on a manta ray.

Measurements of DW were less precise than measurements of DL. This was most likely due to the difficulty in photographing the manta ray with its wings completely open. Even with dead specimens where the fin tips have become curled or the texture has become loose, DW measurements can be unreliable (Notarbartolo-di-Sciara 1987, Marshall et al. 2008), and caution should be taken when using this metric. DL proved to be a more accurate metric for measuring the body size of free-ranging manta rays.

\section{Manta measurements}

For direct comparisons with other studies, DL can be converted to a more conventional DW estimate by applying a DR function. The relationship between DW and DL was constant, regardless of sex or age class. Morphometric proportions, including the DW and DL of a measured male manta ray fetus from southern Mozambique, were the same as those measured for 3 juvenile manta rays from South Africa (Marshall et al. 2008), adding further support for isometric growth of this species.

The mean DR was $2.33(95 \% \mathrm{CI}= \pm 0.02)$, similar to those reported for specimens in South Africa ranging between 2.21 and 2.37, and a fetus from southern Mozambique with a DR of 2.43 (Marshall et al. 2008). DRs for oceanic manta rays include 2.2 reported for an individual from the eastern North Atlantic (Bigelow \& Schroeder 1953) and a range of 2.16 to 2.29 from 4 specimens examined in Indonesia (Marshall et al. 2009).

The largest measured manta ray was a female estimated at $3.64 \mathrm{~m}$ DW, substantially smaller than the $5.50 \mathrm{~m}$ DW maximum estimate observed in southern Mozambique (Marshall et al. 2009) and the $4.30 \mathrm{~m} \mathrm{DW}$ maximum estimate observed in Japan (Kashiwagi et al. 2008). Geographic variability in size is common for oceanic mantas, which range in size from $4.94 \mathrm{~m} \mathrm{DW}$ in Indonesia (White et al. 2006) to $6.45 \mathrm{~m} \mathrm{DW}$ in the eastern North Atlantic (Bigelow \& Schroeder 1953). Additional size measurements of geographically independent populations of Manta alfredi should be investigated for comparison.

The largest measured female was $18 \%$ larger than the largest measured male. This supports the existence of sexual dimorphism in this resident population. The largest measured female manta ray in Japan was $19 \%$ larger than the largest measured male (Kashigawa et al. 2008). It should be noted that measurements in this study were taken by extending a piece of rope between 2 divers positioned above the manta ray as it swam (T. Kashiwagi pers. comm.).

Sexual dimorphism can occur when natural selection for high female fecundity in a species is stronger than sexual selection for males (Wiklund \& Karlsson 1988). In most vertebrates, natural selection for larger males is well understood, with larger males having an advantage in male-male competition for mating access to females (Thornhill \& Alcock 1983). Natural selection can also favor larger females, with larger females having greater fecundity (Fairbairn 1997). Female manta rays give birth to a single, large, well-developed pup every 2 to 3 yr (Homma et al. 1999). Since the pup receives no parental care immediately after parturition, larger pups should have greater survivorship (e.g. McMahon et al. 2000). This immediate independence favors large pups and larger mothers are more able to produce larger offspring (e.g. Pack et al. 2009).

Newborn manta rays have been reported with a DW of 1.1 to $1.5 \mathrm{~m}$ (Homma et al. 1999, Marshall et al. 2009). The absence of manta rays $<2.5 \mathrm{~m}$ DW from the study area suggest that young manta rays may be geographically segregating and may not visit the study area until later in their development. Segregation by body size has been noted for other mobulid species: Mobula thurstoni, M. japanica, M. munkiana, and $M$. tarapacana (Notarbartolo-di-Sciara 1988).

In several species of sharks, females are known to move into specific nursery areas to give birth (e.g. Simpfendorfer \& Milward 1993). The pups remain in the protected area for a length of time before dispersing, presumably for protection against predation. Similarly, female manta rays may retreat to more protected habitats to give birth, where the pup will reside locally until it reaches a certain age or size. Since no female manta ray has been observed giving birth in the wild, it is not yet known where they go to have their young.

Small manta rays have been observed and photographed in shallow waters along Maui's southeastern shores (B. Blinski pers. comm.), but none have been systematically measured. This southeast Maui area is approximately $20 \mathrm{~km}$ from the study site and may constitute an area where females give birth. Future efforts should focus on obtaining body size measurements from manta rays frequenting this area.

Using pregnancy and mating scars as an indicator of sexual maturity in females, a DW of $3.37 \mathrm{~m}$ constitutes a conservative estimate of the size at sexual maturity achieved by females in this Maui population. Although females measuring $3.24 \mathrm{~m}$ DW were observed as nuclear females in mating trains, the lack of observed mating scars and pregnancy suggest immature fe- 
males may also be pursued by males in mating trains. Otherwise, $3.24 \mathrm{~m}$ DW may represent a lower limit on sexual maturity in females. Males appear to reach sexual maturity between 2.75 and $2.80 \mathrm{~m} \mathrm{DW}$, at the time when their claspers grow rapidly and begin to extend beyond their pelvic fins.

\section{Future research}

Paired-laser photogrammetry is a practical tool for collecting and comparing morphometric data on resident manta rays throughout their range. By visiting areas where manta rays aggregate, it is relatively easy to obtain length measurements from a large part of the population in a relatively short period of time. The ability to relate individual identities with morphometrics can be applied to longitudinal studies looking at growth rates, and allows for the incorporation of life history information about those individuals. By measuring the body size of captive and free-ranging animals of known ages, future applications include identifying age-specific survival rates, age at first pregnancy, and other important variables for modeling population growth. Morphometrics on free-ranging manta rays can also help to identify stock depletion, evident from fewer older and larger animals in the population (Cubbage \& Calambokidis 1987), primarily in regions where they are overfished (Marshall et al. 2006, White et al. 2006). This is particularly important with large, slower-growing species such as manta rays, which are at greater risk of population decline from exploitation (Frisk et al. 2001).

\section{Summary}

The equipment needed to carry out paired-laser photogrammetry is simple, allowing a single diver to collect a large number of manta ray measurements quickly, with high accuracy and precision. Information about the individual's identity, sex, and age class can be obtained simultaneously. These types of information from known-aged animals can be applied to population growth models and used for population management. By adjusting the distance between the lasers, the projected points of light can be customized for measurements of other species. Limitations to the use of this system include the ability to fit the target being measured within the field of view of the camera, the distance from the target at which the light points are still visible (largely dependent on the clarity of the water), and the ability to get into position such that the target is perpendicular to the axis of the laser projections.
Acknowledgements. I thank J. Whitney, A. Ligon, Bo Blinsky and E. Lyman for support with data collection, and R. Deakos, S. Spitz, and B. Brainstetter for their assistance with instrument calibrations. Additional thanks go to L. Herman, A. Marshall, T. Adams, J. Deakos, M. Smultea, W. White, J. Kubatko, and anonymous reviewers for valuable feedback on earlier versions of this manuscript, and to J. Mobley for assistance with permit issuance. Research was conducted under the University of Hawaii Animal Care \& Use Committee, Protocol No. 08-591-2, Assurance No. A3423-01.

\section{LITERATURE CITED}

>Adams J, Speakman T, Zolman E, Schwacke L (2006) Automating image matching, cataloging, and analysis for photo-identification research. Aquat Mamm 32:374-384

Bejder L, Fletcher D, Bräger S (1998) A method for testing association patterns of social animals. Anim Behav 56: 719-725

Bell C, Hindell M, Burton H (1997) Estimation of body mass in the southern elephant seal, Mirounga leonina, by photogrammetry and morphometrics. Mar Mamm Sci 13:669-682

Bergeron P (2007) Parallel lasers for remote measurements of morphological traits. J Wildl Manag 71:289-292

Best P, Ruther H (1992) Aerial photogrammetry of southern right whales, Eubalaena australis. J Zool 228:595-614

Bigelow HB, Schroeder WC (1953) Sawfishes, guitarfishes, skates, rays, and chimaeroids. In: Bigelow HB, Schroeder WC (eds) Fishes of the western North Atlantic, Part 2. Sears Foundation for Marine Research, Yale University, New Haven, CT, p 508-514

Brault S, Caswell H (1993) Pod-specific demography of killer whales (Orcinus orca). Ecology 74:1444-1454

Breuer T, Robbins M, Boesch C (2007) Using photogrammetry and color scoring to assess sexual dimorphism in wild western gorillas. Am J Phys Anthropol 134:369-382

Calambokidis J, Steiger G, Evenson J, Flynn K and others (1996) Interchange and isolation of humpback whales off California and other North Pacific feeding grounds. Mar Mamm Sci 12:215-226

Clark TB (2001) Population structure of Manta birostris (Chondrichthyes: Mobulidae) from the Pacific and Atlantic Oceans. MS thesis, Texas A\&M University, Galveston, TX

$>$ Clark S, Odell D, Lacinak C (2000) Aspects of growth in captive killer whales (Orcinus orca). Mar Mamm Sci 16: 110-123

Compagno LJV (1999) Systematics and body form. In: Hamlett WC (ed) Sharks, skates, and rays: the biology of elasmobranch fishes. John Hopkins University Press, Baltimore, MD, p 1-42

$>$ Cosens S, Blouw A (2003) Size- and age-class segregation of bowhead whales summering in northern Foxe Basin: a photogrammetric analysis. Mar Mamm Sci 19:284-296

Cubbage J, Calambokidis J (1987) Size-class segregation of bowhead whales discerned through aerial stereophotogrammetry. Mar Mamm Sci 3:179-185

Dawson S, Chessum C, Hunt P, Slooten E (1995) An inexpensive, stereophotographic technique to measure sperm whales from small boats. Rep Int Whaling Comm 45: 431-436

> Dewar H, Mous P, Domeier M, Muljadi A, Pet J, Whitty J (2008) Movements and site fidelity of the giant manta ray, Manta birostris, in the Komodo Marine Park, Indonesia. Mar Biol 155:121-133

> Durban J, Parsons K (2006) Laser-metrics of free-ranging killer whales. Mar Mamm Sci 22:735-743 
Fairbairn D (1997) Allometry for sexual size dimorphism: pattern and process in the coevolution of body size in males and females. Annu Rev Ecol Syst 28:659-687

Francis M (2006) Morphometric minefields-towards a measurement standard for chondrichthyan fishes. Environ Biol Fishes 77:407-421

Frisk M, Miller T, Fogarty M (2001) Estimation and analysis of biological parameters in elasmobranch fishes: a comparative life history study. Can J Fish Aquat Sci 58:969-981

Gordon J (1990) A simple photographic technique for measuring the length of whales from boats at sea. Rep Int Whaling Comm 40:581-588

Graham R, Roberts C (2007) Assessing the size, growth rate and structure of a seasonal population of whale sharks (Rhincodon typus Smith 1828) using conventional tagging and photo identification. Fish Res 84:71-80

Homma K, Maruyama T, Itoh T, Ishihara H, Uchida S (1999) Biology of the manta ray, Manta birostris Walbaum, in the Indo-Pacific. In: Seret B, Sire JY (eds) Indo-Pacific fish biology: Proc 5th Int Conf Indo-Pacific Fishes, Noumea, 1997. Ichthyological Society of France, Paris, p 209-216

> Jones A, Hall N, Potter I (2008) Size compositions and reproductive biology of an important bycatch shark species (Heterodontus portusjacksoni) in south-western Australian waters. J Mar Biol Assoc UK 88:189-197

Kashiwagi T, Ito T, Ovenden J, Bennett M (2008) Population characteristics of Manta birostris observed in Yaeyama, Okinawa, Japan, 1987-2006. In: Donnelly MA (ed) Joint Meeting of Ichthyologists and Herpetologists, 23-28 Jul 2008, Montreal, Canada. American Society of Ichthyologists and Herpetologists, Miami, FL, p 235 (Abstract)

Klimley A, Brown S (1983) Stereophotography for the field biologist: measurement of lengths and three-dimensional positions of free-swimming sharks. Mar Biol 74:175-185

Langtimm C, Beck C, Edwards H, Fick-Child K, Ackerman B, Barton S, Hartley W (2004) Survival estimates for Florida manatees from the photo-identification of individuals. Mar Mamm Sci 20:438-463

Last P, Stevens J (1994) Sharks and rays of Australia. CSIRO Publishing, Melbourne

Losey G Jr (1972) The ecological importance of cleaning symbiosis. Copeia 1972:820-833

Marshall AD (2009) Biology and population ecology of Manta birostris in southern Mozambique. PhD dissertation, University of Queensland, Brisbane

Marshall A, Ishihara H, Dudley S, Clark T, Jorgensen S, Smith W, Bizzarro J (2006) Manta birostris. In: IUCN (ed) IUCN Red List of Threatened Species. Version 2009.1, available at www.iucnredlist.org

Marshall AD, Pierce SJ, Bennett MB (2008) Morphological measurements of manta rays (Manta birostris) with a description of a foetus from the east coast of Southern Africa. Zootaxa 1717:24-30

Marshall A, Compagno L, Bennett M (2009) Redescription of the genus Manta with resurrection of Manta alfredi (Krefft, 1868) (Chondrichthyes; Myliobatoidei; Mobulidae). Zootaxa 2301:1-28

McMahon C, Burton H, Bester M (2000) Weaning mass and the future survival of juvenile southern elephant seals, Mirounga leonina, at Macquarie Island. Antarct Sci 72: $749-753$

Editorial responsibility: Hans Heinrich Janssen, Oldendorf/Luhe, Germany
Mueller R, Brown R, Hop H, Moulton L (2006) Video and acoustic camera techniques for studying fish under ice: a review and comparison. Rev Fish Biol Fish 16:213-226

> Notarbartolo-di-Sciara G (1987) A revisionary study of the genus Mobula Rafinesque, 1810 (Chondrichthyes: Mobulidae) with the description of a new species. Zool J Linn Soc 91:1-91

Notarbartolo-di-Sciara G (1988) Natural history notes of the rays of the genus Mobula in the Gulf of California. Fish Bull 86:45-66

> Notarbartolo-di-Sciara G, Hillyer EV (1989) Mobulid rays off eastern Venezuela (Chondrichthyes, Mobulidae). Copeia 607-614

> Pack A, Herman L, Spitz S, Hakala S, Deakos M, Herman E (2009) Male humpback whales in the Hawaiian breeding grounds preferentially associate with larger females. Anim Behav 77:653-662

Perryman W, Lynn M (1993) Identification of geographic forms of common dolphin (Delphinus delphis) from aerial photogrammetry. Mar Mamm Sci 9:119-137

> Rowe L, Dawson S (2008) Laser photogrammetry to determine dorsal fin size in a population of bottlenose dolphins from Doubtful Sound, New Zealand. Aust J Zool 56:239-248

Simpfendorfer C, Milward N (1993) Utilisation of a tropical bay as a nursery area by sharks of the families Carcharhinidae and Sphyrnidae. Environ Biol Fishes 37: $337-345$

Spitz SS, Herman LM, Pack AA (2000) Measuring the size of humpback whales (Megaptera novaeangliae) by underwater videogrammetry. Mar Mamm Sci 16:664-676

Swaminathan R, Nayar S (1999) Polycameras: camera clusters for wide angle imaging. CUCS-013-99. Columbia University, New York

Thornhill R, Alcock J (1983) The evolution of insect mating systems. Harvard University Press, Cambridge, MA

Uchida S, Toda M, Matsumoto Y (2008) Captive records of manta rays in Okinawa Churaumi Aquarium. In: Donnelly MA (ed) Joint Meeting of Ichthyologists and Herpetologists, 23-28 Jul 2008, Montreal, Canada. American Society of Ichthyologists and Herpetologists, Miami, FL, p 459 (Abstract)

Visser IN, Bonoccorso FJ (2003) New observations and a review of killer whale (Orcinus orca) sightings in Papua New Guinea waters. Aquat Mamm 29:150-172

Waters S, Whitehead H (1990) Population and growth parameters of Galapagos sperm whales estimated from length distributions. Rep Int Whaling Comm 40:225-235

- White WT, Giles J, Dharmadi, Potter IC (2006) Data on the bycatch fishery and reproductive biology of mobulid rays (Myliobatiformes) in Indonesia. Fish Res 82:65-73

Wiklund C, Karlsson B (1988) Sexual size dimorphism in relation to fecundity in some Swedish satyrid butterflies. Am Nat 131:132-138

Würsig B, Jefferson T (1990) Methods of photo-identification for small cetaceans. Rep Int Whaling Comm 12:43-52

Yano K, Sato F, Takahashi T (1999) Observations of mating behavior of the manta ray, Manta birostris, at the Ogasawara Islands, Japan. Ichthyol Res 46:289-296

Yoshihara K (1997) A fish body length measuring method using an underwater video camera in combination with laser discharge equipment. Fish Sci 63:676-680

Submitted: April 13, 2010; Accepted: May 5, 2010

Proofs received from author(s): June 10, 2010 